\title{
O trabalho do agente comunitário de saúde e a política de atenção básica em São Paulo, Brasil
}

\author{
Maria Luisa Sandoval Schmidt ${ }^{1}$ e Tatiana Freitas Stockler das Neves ${ }^{2}$
}

\begin{abstract}
O artigo analisa parte de pesquisa participante em Unidade Básica de Saúde (UBS) da cidade de São Paulo, Brasil, cujo objetivo é compreender aspectos da implementação do Programa de Saúde da Família (PSF) como política pública de atenção primária no embate com modelo médico-assistencial hegemônico no país. Expõe elementos de possível articulação entre pesquisa interventiva participante e formação em serviço, conformando proposta de pesquisa em que a colaboração dos participantes define seus rumos e desdobramentos. Por fim, apresenta duas situações exemplares do cotidiano da UBS, priorizando: a) dimensão política das relações de saber-poder nas equipes de PSF e destas equipes com outros profissionais da unidade e b) dimensão ideológica por meio das representações de si e dos outros nas relações de trabalho, contemplando a dinâmica do par identidade/alteridade. A análise revela, entre outros, a centralidade do agente comunitário de saúde (ACS), a quem se atribui papel de intermediário entre sistema público de saúde e população usuária dos bairros/comunidades pobres da cidade. Esse lugar de fronteira dos ACSs sofre e denuncia contradições e tensões de uma política cujas metas são definidas à revelia da experiência/saberes populares e que, concretamente, reforça os lugares de saber-poder estatais.
\end{abstract}

Palavras-chave: Políticas públicas, Saúde, PSF, Agente comunitário de saúde, Pesquisa participante, Cotidiano de trabalho.

The work of the community healthcare agent and the basic healthcare policy in São Paulo, Brazil

This paper examines part of the participating research developed at the Healthcare Basic Unit (UBS) of São Paulo city (Brazil), whose aiming at understanding the implementation aspects of the Family Healthcare Program (PSF) as a public primary care policy, facing the hegemonic assistentialist medical model within the country. It shows possible articulation elements between the participating intervening research and in-service education, shaping a research proposal where participants' cooperation defines its own development and unfolding. Finally, it brings two examples of the UBS day-by-day, prioritizing: a) the political dimension of the knowledge-power relationships within the PSF teams and between these teams and other professionals working at the unit, and b) the ideological dimension by means of the representations of themselves and the other people in the working relationships, considering the identity/alterity dynamics. Among others issues, the analysis reveals the centrality of the healthcare community agent (ACS), who impersonates an intermediating role between the public healthcare system and the users from the city low-income neighbors/communities. This bordering place of the ACSs encounters and denounces the contradictions and stresses of a policy whose goals are defined without considering the popular experience/knowledge, that really reinforces the places of the governmental knowledge-power.

Keywords: Public policies, Healthcare, PSF, Healthcare community agent, Participating research, Working day-byday.

$\mathrm{O}$ presente artigo visa analisar parte de material de campo de pesquisa participante que vem sendo realizada junto a uma Unidade Básica de Saúde (UBS) do sistema público de saúde do município de São Paulo, Brasil. A pesquisa tem por objetivo geral compreender elementos políticos e ideológicos do Programa de Saúde da Família (PSF), que se apresenta, no plano nacional, como estratégia privilegiada e hegemônica de atenção básica.

A pesquisa, iniciada no final de 2005, angariou um conjunto extenso de observações e vem acompanhando a UBS em um processo que requer dos trabalhadores, por um lado,

1 Docente do Departamento de Psicologia da Aprendizagem, do Desenvolvimento e da Personalidade do Instituto de Psicologia da Universidade de São Paulo (IPUSP). Coordenadora do Serviço de Aconselhamento Psicológico (SAP) do IPUSP. Coordenadora do Laboratório de Estudos do Imaginário (LABI) do IPUSP e do Núcleo Interdisciplinar do Imaginário e da Memória (NIME) da USP.

2 Psicóloga, pesquisadora e supervisora de estágios do Centro de Psicologia Aplicada ao Trabalho (CPAT) do Departamento de Psicologia Social e do Trabalho do IPUSP. Pesquisadora e integrante do Laboratório de Estudos do Imaginário (LABI) do IPUSP e do Núcleo Interdisciplinar do Imaginário e Memória (NIME) da USP. 
compreensão, apropriação e realização da proposta do PSF em condições distantes das ideais no que diz respeito a formação, salário, carga de trabalho, estrutura material, entre outros aspectos. Por outro, como é relativamente comum na implementação de políticas públicas de saúde no Brasil, exige adaptação constante dos trabalhadores às inconstâncias dos mandatos e dos interesses de governo que, muitas vezes, não se mostram a favor do tempo e da elaboração intelectual e prática necessários à construção de um programa de cuidado e de atenção consequentes mas, ao contrário, têm significado demagógico ou publicitário (Cohn \& Elias, 2005).

Trata-se de um percurso aberto a várias linhas de interpretação das relações de poder (Foucault, 1980, 1981) e do jogo das representações do par identidade/alteridade (Augè, 1997; Geertz, 1989a) nas práticas da UBS, tais como: constituição do poder e das mútuas representações no interior das equipes de PSF formadas por médicos, enfermeiros, auxiliares de enfermagem e agentes comunitários de saúde; formas de gestão das equipes de atenção e do programa; representações de saúde e doença; modos de cuidado e de atenção e suas representações; adesões e oposições às ordens de governo; entendimento e desconhecimento das prescrições dos gestores de governo e suas "intenções" políticas; tensão e diferença entre trabalho prescrito e trabalho real (Sato, 2002), entre outros.

Para esta exposição, fez-se a escolha pela análise das práticas da UBS enfatizando a persistência do modelo médico-assistencial nos modos de apropriação e de realização do PSF e suas relações com a construção do lugar do agente comunitário de saúde. Em São Paulo, as tensões e os embates entre o modelo médico-assistencial e aquele da promoção e da prevenção acontecem na atmosfera de interesses econômicos e políticos voltados para o controle do sistema de prestação de serviços em saúde (Augusto, 1989; Cohn, 2003; Junqueira, 2001).

Explicações sobre o sistema nacional de saúde, o PSF e a metodologia da pesquisa precedem a análise, oferecendo um contexto no qual esta pode fazer sentido.

\section{Programa de Saúde da Família e Sistema Único de Saúde}

Em 2008, o Sistema Único de Saúde (SUS) completou 20 anos, tendo sido formulado como política unificada de saúde para todo o território brasileiro em 1988, após a reforma constitucional que tornou a saúde um direito de todos, garantido como dever de Estado.

O SUS é responsável pelo atendimento de toda a população do Brasil, seguindo os princípios de descentralização, regionalização e hierarquização dos serviços e propondo o controle público de suas ações, que devem ter um caráter único, integral e universal.

As ideias de promoção da saúde e de prevenção, presentes no SUS, indicam, por um lado, a relação da saúde com as condições de vida e com a produção de igualdade social, traduzida em oportunidades dignas de trabalho, educação, moradia, alimentação, lazer, entre outras e, por outro, a necessidade de questionar a redução da atenção em saúde à assistência médica.

Esse sistema aspira e busca a democratização do atendimento à saúde, a história de sua implantação e implementação, no entanto, apresenta problemas, entre os quais é possível destacar dois bastante persistentes: as dificuldades de financiamento e a alta demanda por assistência, que faz as ações de promoção e prevenção encolherem e reforça a hegemonia do modelo médico-assistencial nos diferentes serviços de saúde (Cohn, 2005).

O PSF, cujas primeiras experiências datam do começo da década de 90, tem sido apontado como estratégia capaz de atender aos princípios e metas do SUS, enfrentando, de modo especial, os problemas acima referidos. 
Essa é a posição de autores como Viana e Dal Poz (2005), que consideram o PSF como uma espécie de reforma incremental do SUS, com habilidade para superar tanto a carência de recursos financeiros, quanto a quase exclusividade do modelo médico-assistencial no atendimento à saúde. Seus argumentos, no âmbito das vantagens financeiras do PSF, destacam a forma de repasse das verbas federais para os municípios calculada a partir de um montante fixo por habitante, a flexibilidade e a abertura para parcerias com instituições públicas e privadas para a gestão de equipamentos e serviços e, ainda, a existência de diferentes tipos de contratação de funcionários, evitando o regime próprio do funcionalismo público e, com isso, certos encargos trabalhistas que, em tese, onerariam o Estado. No que diz respeito à organização da atenção, o PSF é, para seus defensores, um poderoso instrumento de mudança do modelo assistencial centrado no atendimento médico, principalmente pelo fato de agir junto à população por meio dos agentes comunitários de saúde, focalizando a prevenção e a promoção aliadas à mobilização política em torno da melhoria das condições de vida nos bairros e nas comunidades pobres das cidades.

Perspectivas críticas ao PSF também o enxergam como reforma do SUS, porém com intenções diversas daquelas apontadas por seus defensores: trata-se de reforma que não procura a consecução dos princípios e metas do sistema, mas sim a reapropriação privada dos recursos públicos destinados à saúde.

Virginia Junqueira (2001), ao desaprovar o PSF, destaca seu caráter compulsório de programa-modelo imposto pelo governo federal que, por isso, deixa de atender às singularidades e necessidades locais de municípios e regiões, servindo, no entanto, à privatização generalizada de serviços e equipamentos. A porta para a privatização é sobretudo aberta pelas parcerias entre as instituições públicas e as organizações privadas, aliadas à precarização dos contratos de trabalho. Como aponta a autora, na cidade de São Paulo, por exemplo, os convênios do SUS são majoritariamente com planos e seguros privados de saúde e a atenção básica, nos moldes do PSF, serviria como seletor de demandas por serviços mais sofisticados e caros, interessantes para os convênios. Há, ainda, a compra, pelo PSF, de serviços de organizações sociais, terceirizando "partes" dos equipamentos e das tarefas e criando incompatibilidades entre formas e regimes de trabalho, às vezes, no interior de uma mesma equipe ou instituição.

Apesar das possíveis "boas intenções" da proposição do PSF e de resultados positivos alcançados em algumas áreas, como o controle de doenças crônicas, o acompanhamento pré e pós natal e seus efeitos na diminuição de mortalidade infanto-materna, o combate a endemias e epidemias, as campanhas de vacinação, entre outras, é visível que o PSF sofre dos mesmos males que o SUS: questões e tensões em torno do financiamento assumem, em determinadas cidades como São Paulo, matizes dramáticos por colocarem em curso processos de "loteamento" da rede de equipamentos e serviços que põem em risco a própria natureza pública do sistema e a hegemonia do modelo médico-assistencial está longe de ser superada ou, pelo menos, mantida em equilíbrio com outras formas de cuidado e de saber (Augusto Junior et al., 2009; Cohn, 2003; Gil, 2005; Junqueira, 2001).

Na UBS analisada, está sendo possível seguir mudanças que caminham na direção dessa privatização. A criação do PSF, no ano de 2004, é reportada pelos trabalhadores como ato de governo que pouco ou nada lidou com a situação singular daquela unidade, na qual existia um trabalho estruturado nos moldes da atenção primária "tradicional", praticada, sobretudo, como consultas realizadas por profissionais de diferentes especialidades (clínico geral, pediatra, obstetra, ginecologista, psiquiatra, psicólogo, fonoaudiólogo e dentista), apoiados por um setor administrativo composto por profissionais, como os especialistas, funcionários públicos de carreira. 
Agentes comunitários de saúde foram selecionados e "alocados" na unidade sem preparação prévia e sem o suporte de outros profissionais previstos para a equipe mínima de PSF. Os contratos desses agentes, por sua vez, foram feitos por uma fundação parceira do governo municipal, em caráter experimental. Instituída "por decreto", a proposta de saúde da família, nesse caso, não é objeto de discussão, reflexão ou planejamento conjunto, mas é justaposta ao modelo pré-existente, como "novidade" a ser incorporada pela unidade de forma automática e não-problemática.

A figura dessa justaposição é a chamada Unidade Mista que, mais recentemente, vem sendo alvo de ações que preparam sua passagem, como um todo, para as mãos de fundações ou organizações sociais (SMS-SP, 2009). Fundações e organizações sociais, na cidade de São Paulo, tornam-se, em curso crescente, responsáveis pela gestão e pela execução das políticas públicas de saúde, que, no entanto, continuam a ser financiadas pelas verbas públicas. Nesse processo, os trabalhadores, funcionários públicos de carreira ou contratados para o PSF, são tratados como parte do patrimônio que vem sendo negociado, vivendo um período de intensa insegurança e desconhecimento quanto aos seus destinos profissionais e quanto aos destinos do próprio serviço que prestam. Observa-se desconsideração pelos processos organizativos e de trabalho (Spink, 1996) e pelos trabalhadores em favor dos interesses políticos e de privatização.

A privatização dos serviços públicos está no horizonte de intenções de governantes brasileiros desde a Reforma de Estado dos anos 90, proposta pelo ministro Bresser Pereira (Brasil, 1997, 1998, 1999, 2000; Gonçalves, 1998; Montaño, 2002; Oliveira, 2001; Pierantoni, 2001; Silva Junior \& Sguissardi, 1999). Os setores da educação e da saúde vêm resistindo a essa privatização e nem todos os municípios do país experimentam o mesmo ritmo de transformações a que a cidade de São Paulo assiste nos últimos quatro anos, tendo em vista tendências e alianças partidárias em níveis municipal ${ }^{4}$, estadual e federal.

A visão do PSF como dispositivo de privatização, tal como Junqueira (2001) apregoa, carece ser relativizada, pois em outros municípios ${ }^{5}$ é conduzido com recursos públicos, em instituições públicas e por funcionários públicos, como política de atenção básica hegemônica e "recomendada" pelo governo federal.

Por isso, mesmo no caso de São Paulo, em que o processo de privatização vem se realizando com mais intensidade, é preciso considerar as tensões e os conflitos nesse processo junto àqueles inerentes a um modelo de atenção básica que quer enfrentar e, talvez, superar, a dominância do modelo médico-assistencial.

Para compreender essas injunções, faz-se necessária uma exposição, ainda que breve, das ideias e práticas que definem o PSF.

Como já dito anteriormente, o PSF compartilha o ideário do SUS acerca de prevenção e promoção de saúde (Bouquat, Cohn \& Elias, 2006; Viana \& Dal Poz, 2005). Trata-se de proposta voltada para as populações mais pobres dos grandes centros urbanos, consideradas como aquelas que correm maiores riscos de agravos à saúde. A atenção é organizada em torno de equipes mínimas, formadas por um médico, seis agentes comunitários, um enfermeiro e um

\footnotetext{
4 De 1993 a 2000, sob os governos municipais de Paulo Salim Maluf e Celso Pitta, a cidade de São Paulo teve o Programa de Atendimento à Saúde (PAS), constituído por organizações denominadas "cooperativas" de prestação de serviços financiadas pelo poder público com verbas públicas (Augusto Junior et al., 2009). Foi um outro modelo de privatização que impediu, inclusive, a municipalização dos equipamentos e dos serviços de saúde prevista no SUS. A partir de 2001, no governo de Marta Suplicy, houve a municipalização que consubstancializa o SUS na cidade. No que diz respeito ao Programa de Saúde da Família, nesse governo, foram estabelecidas parcerias público/privadas sem as quais se acreditava que não seria possível a constituição das equipes daqueles programa (Alves Sobrinho \& Capucci, 2003; SMS-SP, 2001). No governo seguinte de Serra/Kassab (2005 a 2008), houve uma intensificação do papel das organizações privadas na condução das políticas públicas da cidade, culminando com a transferência da gestão plena de unidades de PSF para essas organizações (no governo de Kassab que se iniciou em 2009). Ver Portaria 1590/2009 da SMS-SP.
}

5 Sabemos que essa afirmação é válida para municípios como, por exemplo, Recife, Vitória, Porto Alegre, a partir de comunicações orais em congressos sobre o tema. 
auxiliar de enfermagem, responsáveis por um território ou área geográfica compostos por $800 \mathrm{a}$ 1000 famílias.

A família passa a ser, em tese, no ideário da proposta do PSF, o núcleo básico do atendimento, sendo contexto e objeto de ações tanto de assistência, quanto educativas. Percebe-se, ainda, a família como unidade compreensiva, que tenta superar as abordagens individuais e individualizantes do par saúde/doença e como parte de uma existência comunitária imaginada como própria dos bairros pobres e favelas das grandes cidades como São Paulo.

O apelo à promoção e à prevenção, implicando o trato com problemas sociais e a mobilização política para a melhoria de condições de vida, encarna a busca de superação da concepção de saúde restrita ao biológico, assim como a abordagem familiar investe na superação do assistencialismo individual.

O agente comunitário de saúde, no PSF, é a "novidade" na qual são depositadas as esperanças de transposição, no plano prático, de um modelo centrado no conhecimento e na ação médicos e no atendimento individual fundamentado na cura de doenças.

De início, é preciso dizer que o agente comunitário deve ser recrutado no próprio bairro em que irá atuar. $\mathrm{O}$ argumento para esse tipo de recrutamento é, justamente, o interesse de trazer para o sistema público de saúde alguém cujos conhecimentos, familiaridade e inserção locais possam produzir uma leitura mais representativa das necessidades das demandas de seu bairro ou de sua comunidade, constituindo-se, ao mesmo tempo, como mobilizador da participação popular nos planos político e educativo. Além dessas tarefas de representação e organização popular, há, por outro lado, a atribuição de funções de vigilância e de controle sanitários, em que o agente comunitário é requerido não mais como representante da população, mas sim como porta-voz do sistema de saúde. Idealmente, trata-se de imaginar um profissional capaz de estabelecer pontes e vias de comunicação entre os modos de vida e saberes populares e as formas de cuidado e controle informadas pelos saberes científicos especializados.

Em pesquisa sobre a identidade profissional de agentes comunitários na cidade de São Paulo, Silva e Dalmaso (2002) abrem interessantes dimensões dessa profissão que vem se construindo como profissão de fronteira e prática híbrida, pela posição do ACS entre o sistema de saúde e a população de usuários desse sistema concebida como comunidade.

$\mathrm{Na}$ investigação das práticas dos agentes comunitários em seu cotidiano de trabalho e das representações de si e dos outros, algumas revelações merecem ser destacadas.

A mais contundente, talvez, seja a constatação de que a prática do agente comunitário é capturada pela prevalência do modelo médico-assistencial no interior de um programa que tenta superá-lo. Na descrição das ações desses agentes, sobressaem-se a atenção e o controle de riscos (controle de medicação, marcação de exames etc.) e conversas sobre assuntos variados do cotidiano, da vida da cidade, entre outros. Destacam-se, também, a dupla função de oferecer informações para os usuários sobre serviços e orientações médicas e informações sobre os usuários para os especialistas dos equipamentos públicos de saúde, colhidas nas visitas domiciliares. Nessas ações dos agentes, é perceptível o quanto estão aderidos aos enfoques orgânico e comportamental dos problemas dos usuários (Silva \& Dalmaso, 2002). Esse enfoque, por sua vez, relaciona-se com a formação que é dada aos agentes em grande parte das unidades básicas de saúde e com as expectativas em relação ao seu papel.

As representações, no jogo identidade/alteridade, convergem em muitos pontos e explicitam duas regiões de tensões e ambivalências que assinalam a identidade do agente comunitário como sendo de fronteira, quais sejam, entre o político e o técnico e entre o comunitário e o institucional.

$\mathrm{Na}$ formulação da proposta de PSF, como já foi insinuado antes, os agentes são definidos por duas esferas de atuação principais: a) mobilizadores da população para promoção 
de saúde e b) vigilância e controle de vulnerabilidade, especialmente de doenças crônicas (por exemplo, hipertensão e diabete), endemias e epidemias e saúde infanto-materna.

Os próprios agentes veem-se como intermediários entre a família, o mundo exterior e a equipe de saúde; cuidadores, apoiando as famílias nos momentos de necessidade ou sofrimento; observadores qualificados da situação de saúde e das necessidades da família. Há, também, uma preocupação dos agentes com diferençar-se da população e nessa preocupação é possível reconhecer uma via de aproximação e identificação com a instituição médica.

Os médicos, por sua vez, ao considerarem a presença dos agentes como um "diferencial" do PSF em relação a outros programas de atenção básica, têm uma visão desses profissionais como uma espécie de prolongamento de si mesmos. No dizer significativo de um médico: "O agente foi colocado estrategicamente para incomodar o médico, mas eles são os meus tentáculos. Ele que vê, que sente, que sabe (...)" (Silva \& Dalmaso, 2002, p. 172).

Entre as enfermeiras aparecem representações dos agentes como comunicadores por excelência. Essa comunicação diz respeito à sua capacidade de conversar com a população, especialmente para interrogá-la sobre a adesão a tratamentos e orientações, fiscalizando quem está ou não os seguindo corretamente.

A população, por sua vez, tem a expectativa de ver atendida sua "demanda espontânea de modo imediato e por profissional universitário, médico ou enfermeiro" (Silva \& Dalmaso, 2002, p. 180).

Essas representações exibem a identidade de fronteira dos agentes como embate das expectativas depositadas pelos propositores do PSF e os diferentes lugares construídos nas relações entre médicos, enfermeiros, agentes, gestores e usuários (Nunes et al., 2002; Viana \& Dal Poz, 2005).

Nos tensionamentos entre os polos técnico e político, institucional e comunitário, as autoras da pesquisa interpretam que existe uma tendência de predominância dos polos técnico e institucional na constituição identitária dos agentes comunitários, embora os polos político e comunitário continuem presentes como aquilo a que se aspira e que precisa ser construído (Silva \& Dalmaso, 2002).

Em decorrência dessa interpretação, as autoras avaliam que reuniões e supervisões são espaços profícuos para a formação dos agentes e para a mudança de mentalidade de médicos e enfermeiros, como também apontam Araujo (2005), Campos (1999), Buchabqui, Capp \& Petuco (2006), Lotta (2006), dentre outros.

Essa avaliação parece pertinente na medida em que as reuniões e supervisões são práticas propícias à escuta das diferentes formas de cuidado e de saberes e, em consequência, à elaboração de formas híbridas de compreensão e de atenção. Porém, é necessário que se configurem como lugares em que a formação em serviço seja apropriação e reflexão da prática e não treinamento prescritivo.

\section{Pesquisa interventiva e formação em serviço}

As equipes multiprofissionais do PSF são, como dito anteriormente, do ponto de vista institucional, depositárias de expectativas de mudanças efetivas no modelo de atendimento à saúde. As ações de atenção básica dependem do trabalho integrado de diferentes profissionais, incluindo o papel estratégico dos agentes comunitários. Essa integração ou articulação, contudo, requer a elaboração de lugares de poder-saber deslocados ou modificados em relação ao modelo médico-assistencial, de tal forma que a constituição de uma equipe demanda muito 
mais do que a mera contratação dos profissionais e sua alocação em uma mesma unidade. $O$ planejamento ou a concepção do trabalho cooperativo passa, necessariamente, por novos e diferentes arranjos de lugares de saber e de poder e exige abertura e disposição para uma participação intelectual e afetiva na construção da equipe e do trabalho.

Parte-se, aqui, da pressuposição de que a pesquisa participante de tipo interventiva pode contribuir para a formação em serviço, oferecendo referências e práticas fecundas para as equipes e para o trabalho cooperativo.

O nome pesquisa interventiva procura dar conta daquilo que, da perspectiva fenomenológica e existencial, é constitutivo da investigação na área das ciências humanas e sociais, ou seja, a propriedade intrusiva e modificadora da presença do pesquisador em um campo de relações (Critelli, 1996).

Esse caráter intrusivo e modificador do movimento que o pesquisador faz em direção a um outro é, paradoxalmente, desejo de compreender e de encontrar este outro. Seria possível dizer que a modalidade de pesquisa interventiva de inspiração fenomenológica e existencial busca retomar temas e preocupações da etnografia clássica, a partir da antropologia interpretativa dos anos 70, focalizando, principalmente, a noção de alteridade e a necessidade de autorreflexão pelo pesquisador: situar-se em relação ao outro (Geertz, 1989a) e problematizar, constantemente, o desejo de domínio e de controle dos rumos da pesquisa são ocupações que fundamentam o percurso interventivo.

Embora não seja viável, nem razoável, estabelecer fronteiras rígidas entre compreender, agir e aprender, uma valorização da função compreensiva pode ajudar a respeitar os modos de ser e de fazer de indivíduos e grupos. Esse respeito, por sua vez, designa a pesquisa como espaço de construção de saberes compartilhados, diferentemente daqueles de treinamento, capacitação, atualização ou reciclagem profissional (Neves, 2006). A aposta no poder formativo de uma pesquisa interventiva reside na apropriação do sentido político da convivência e do agir coletivos (Arendt, 1998; 2008; Schmidt, 2003), permitindo ver as situações de encontro e de reunião como exemplos do agir político, dado que ali se combinam a pluralidade de pontos de vista e a chance de singularização de cada trabalhador na consideração de assuntos comuns relativos ao trabalho.

A afinidade com a etnografia, para reafirmar uma ideia importante na conceituação da pesquisa interventiva, configura a pesquisa como trabalho constante de posicionamento de uns diante de outros e de uns e outros em relação ao encontro. Assim, os efeitos de conhecimento sobre algo que interessa a uns e outros ocorrem junto ou em diálogo com efeitos de reconhecimento/desconhecimento/estranhamento de uns em relação a outros: outra maneira de dizer que o jogo identidade/alteridade e a autorreflexão são a atmosfera do empreendimento da pesquisa interventiva.

Dessa conceituação de fundo deriva que a pesquisa assim proposta tem um interesse pela produção de conhecimento compartilhado entre indivíduos e grupos, considerando que a possibilidade mesma desse conhecimento ancora-se, também, nos efeitos de reconhecimento e de estranhamento das diferenças.

O adjetivo interventiva tenta, como já se disse, dar conta da intrusão de um pesquisador ou de uma equipe de pesquisadores no cotidiano de outros, distantes ou próximos. Mas tenta, ainda, nomear, mesmo que precariamente, a dupla faceta de um trabalho que, na psicologia, mas não exclusivamente, une pesquisa e atuação profissional no atendimento de uma demanda. Essa dupla faceta requer, outra vez, o cuidado com a construção democrática da intervenção, implicando na gestão cooperativa dos modos de interpretar as necessidades e no esclarecimento das demandas.

Com a etnografia, a pesquisa interventiva divide, também, a valorização da experiência e a abertura para a polissemia e a polifonia, induzindo a interesse por diversas vozes. O lugar da 
intervenção pode, por essa razão, ser um lugar plural de manifestação de singularidades.

Como lugar plural, a pesquisa interventiva cria e necessita de diferentes e variados contextos em que grupos e coletivos se apresentam. Os grupos são a referência principal na condução da pesquisa e não lugar de aprendizagem instrumental. Neles, a elaboração de conhecimento compartilhado sobre as situações que pedem esclarecimento e a experiência de gestão democrática dos rumos do trabalho se encontram: trata-se do local das decisões e das sínteses interpretativas. A constituição do grupo ou do coletivo como comunidade interpretativa é, em si, tarefa ou empreitada que caminha junto com a tarefa de compreender e intervir naquilo que há para compreender e intervir. Outros contextos como os de entrevistas, coleta de depoimentos e histórias de vida, observação participante de situações cotidianas do trabalho institucional, experimentos com a escrita e demais formas de registro e comunicação dos achados da pesquisa, entre outros, podem desdobrar-se do grupo ou coletivo maior, oferecendo oportunidades de trabalho cooperativo em composições menores.

As conversas informais e a convivência em campo são, como na etnografia, meios preciosos da proposta. E, como na etnografia, a escrita é convocada como veículo do trabalho. Há, como na abertura para invenções metodológicas, uma abertura para diferentes planos de escrita, nos quais anotações do tipo caderno de campo feitas pelos participantes e textos elaborados de registros e interpretações se complementam.

Com isso, espera-se ter clarificado uma forma de pesquisa que supõe a participação do "pesquisado" como produtor de conhecimento, como propositor de metodologias e como trabalhador que decide e age autonomamente no âmbito de sua instituição (Bosi, 1979; Bourdieu, 1997; Geertz, 1989b; Oliveira, 2006; Patto, 2009; Schmidt, 2006, 2008).

\section{Contexto e histórico de uma pesquisa interventiva em UBS de São Paulo}

O projeto de pesquisa-intervenção objeto desta comunicação teve origem na busca, por parte de alguns agentes comunitários de uma UBS da zona oeste de São Paulo, de atendimento psicológico junto ao Serviço de Aconselhamento Psicológico (SAP) ${ }^{6}$ do Instituto de Psicologia da Universidade de São Paulo (IPUSP), no segundo semestre de 2005. Atendidos por estagiários das disciplinas de aconselhamento psicológico no plantão psicológico, cinco agentes abriram, no relato de seu sofrimento e mal-estar na ocasião, aspectos relevantes de sua relação com o trabalho. Estagiários e supervisores envolvidos nos atendimentos individuais desses agentes avaliaram que a proposição de um atendimento grupal, focalizando as vicissitudes e as dificuldades enfrentadas no cotidiano de trabalho dos agentes comunitários, poderia ser interessante e útil (Certeau, 1994).

Estabeleceu-se uma parceria entre o SAP e o Centro de Psicologia Aplicada ao Trabalho $(\mathrm{CPAT})^{7}$ do IPUSP para realização do atendimento proposto.

Foram sugeridos encontros grupais com os agentes que se mostrassem interessados, sem prejuízo do atendimento individual, psicoterápico, dos agentes que já vinham sendo atendidos no SAP ou por algum psicoterapeuta conveniado.

\footnotetext{
6 O SAP é um serviço-escola que oferece estágio supervisionado aos alunos de graduação de psicologia e atendimento psicológico à comunidade uspiana e população em geral. Sua porta de entrada é um plantão psicológico, que acontece semanalmente, acolhendo e trabalhando as demandas de todos os clientes que chegam no período a ele destinado.

7 O CPAT realiza pesquisas, assessorias e atividades de formação a alunos de psicologia no campo da psicologia social do trabalho, focalizando temas relativos ao mundo do trabalho e das organizações. O conhecimento nas áreas de saúde do trabalhador e de processos organizativos justificou sua colaboração nesta pesquisa interventiva.
} 
Os agentes entraram em contato com os colegas e estes demonstraram, em sua maioria, interesse em participar dos grupos.

Os grupos foram então organizados a partir de reuniões dos estagiários com os agentes e de contatos com a coordenação do Programa de Saúde da Família da UBS.

Foram constituídos três grupos, dois com nove agentes e um com seis. Foram programados sete encontros, com periodicidade semanal, para acontecerem ao longo do primeiro semestre de 2006. A equipe foi constituída pelas autoras que conduziram uma equipe de doze estagiários ${ }^{8}$.

Os encontros revelaram um conjunto significativo de temas enlaçando identidade profissional dos agentes, suas motivações e angústias no trabalho, relacionamento com a proposta do PSF e com os outros profissionais do programa e da UBS, condições de trabalho e saúde do trabalhador, processos organizativos na UBS, entre outros.

Ao final do semestre, na avaliação dos encontros, os agentes entenderam que o trabalho realizado ganharia peso e sentido se e quando fosse possível comunicá-lo ao restante dos companheiros da UBS: colegas de equipes de PSF, profissionais especialistas, pessoal administrativo.

O segundo semestre de 2006 foi dedicado à construção coletiva de um texto de síntese do conteúdo discutido nos grupos e à necessária negociação sobre o quê e como comunicar esse conteúdo em uma reunião geral da UBS.

O processo de escritura do texto até sua versão consensual final foi acompanhado por todos os agentes, diretamente em reuniões conjuntas e, algumas vezes, por meio de representantes.

Em fevereiro de 2007, foi feita a apresentação, organizada em três eixos: 1) problemas do trabalho e saúde do trabalhador; 2) possíveis soluções e 3) apreciação do trabalho de grupo.

Quanto ao primeiro item, foram destacados alguns conteúdos, tais como: as motivações para a escolha profissional de ser agente comunitário de saúde, incluindo a memória do início da atividade do PSF naquela UBS e aspectos da relação com funcionários da prefeitura que já atuavam ali; identidade do agente, em que as funções de elo de ligação entre a comunidade e o sistema de saúde, a desejável exemplaridade que esse profissional deve exibir e a mistura entre vida profissional e vida pessoal destacam-se de modo evidente; fontes de sofrimento no trabalho tais como ter que acompanhar vizinhos e conhecidos em suas doenças, intensidade das jornadas de trabalho, medo de falar diante dos hierarquicamente superiores, impotência diante de demandas e necessidades da população, pressão para cumprir metas quantitativas sob ameaça de demissão, dificuldades de reconhecimento e de comunicação entre os agentes e entre eles e outros profissionais; problemas de saúde relacionados com o trabalho, como fibromialgia, depressão, perda de memória; preconceito e desvalorização em relação a seus conhecimentos e tarefas, entre outros.

Nas possíveis soluções, foram referidas democracia, união e respeito nas relações institucionais, melhor capacitação profissional e melhores salários e reconhecimento do lugar do agente comunitário por parte dos outros profissionais.

O trabalho dos grupos teve apreciação positiva com manifestação de interesse pela sua continuidade em outros moldes, ou seja, incluindo outras esferas da UBS. Alguns manifestaram a expectativa de que a condução ou coordenação dos grupos por parte da equipe da USP tivesse sido mais assertiva quanto a oferecer orientações e, por fim, houve a clarificação de um

8 Os estagiários eram alunos do nono semestre. Cita-se a seguir seus nomes: Bruna Ronchi Oliveira, Cássia G. Gomes, Cíntia M. Honda, Cíntia Vasques Hélcias, Emília Lieberg, Fabiana Olivieri Catanzaro, Kelly Dias Peixoto, Letícia L. Carvalho, Maira G. Cursino, Marcos Lanner de Moura, Rafael Baioni do Nascimento e Renato Mori Rodrigues. 
desejo de que a equipe da USP funcionasse como mediadora das reivindicações e das necessidades dos agentes.

Nessa apresentação, surgiu a proposta de que a equipe de psicólogos e pesquisadores do Instituto de Psicologia da USP acompanhasse as reuniões mensais da unidade durante aquele ano de 2007. Essas reuniões aconteceriam em dois horários, facilitando a presença de um maior número de trabalhadores de todos os setores (inclusive o administrativo), sem necessidade de interrupção do funcionamento da UBS.

A proposta foi aceita, configurando as reuniões como espaço de discussão de temas emergentes do cotidiano de trabalho e região de diálogo entre os diferentes profissionais da UBS. Essa aceitação incluiu, também, aprovação da coordenação regional.

Inicialmente, combinou-se que as reuniões seriam divididas em dois momentos: primeiro, uma sessão de informes coordenada pela direção da UBS e, depois, a apresentação e a discussão de temas emergentes, coordenadas pela equipe do IPUSP.

Ao longo do ano, aconteceram nove encontros em cada horário (total de dezoito), com durações de duas a três horas, com a participação de agentes comunitários de saúde (ACSs), auxiliares de enfermagem (AEs), auxiliares técnico-administrativos (ATAs), enfermeiros, médicos, fonoaudióloga, vigia, educador, dentista (totalizando por volta de oitenta pessoas).

Após as primeiras reuniões, a equipe do IPUSP avaliou que seria mais interessante colocar-se no lugar de facilitadora do processo de discussão e não no de coordenadora das reuniões. Essa mudança ocorreu de modo mais ou menos espontâneo tendo em vista: a) o fato de que o momento inicial de informes desdobrava-se já em temas e assuntos de interesse para o debate, não havendo, portanto, a marcação clara de separação entre informes e discussão, mas, ao contrário, o imbricamento de um e outra de maneira dinâmica; b) que a posição de observador participante desde uma perspectiva etnográfica tornou-se mais pertinente para a inserção da equipe que, embora interviesse com comentários e apontamentos, não se incumbiu da coordenação, que ficou com a direção da UBS em todo o processo.

Nessa fase, a equipe do IPUSP era composta pelas duas autoras como coordenadoras, três psicólogos/pesquisadores e três estagiários de graduação. ${ }^{9}$

Para a equipe do IPUSP, o acompanhamento das reuniões teve ramificações em outras esferas, como, por exemplo, a participação em eventos importantes para a instituição (festas, comemoração do aniversário da UBS, III Encontro "Práticas integrativas e medicinas tradicionais: promovendo saúde e cultura de paz no município de São Paulo" ${ }^{10}$ ), orientações sobre saúde do trabalhador, encaminhamentos para atendimento psicológico e psiquiátrico, elaboração de projeto de pesquisa ${ }^{11}$ para obter financiamento junto à FAPESP e sua discussão com representantes das diferentes categorias profissionais da UBS, elaboração de projeto de iniciação científica ${ }^{12}$ junto ao $\mathrm{CNPq} .{ }^{13}$

Do conjunto extenso e rico de temas e situações tratados nas reuniões, foram selecionados dois, considerados emblemáticos, para análise.

9 Cíntia Vasques Hélcias, Kelly Dias Peixoto e Marcos Lanner de Moura, psicólogos/pesquisadores e André Rostworowski, Caio Ernane de Lima Pereira e Ronaldo Lopes Coelho, estagiários de psicologia.

10 Esse encontro, organizado pela Secretaria Municipal de Saúde de São Paulo (CODEPPS), aconteceu em 25 de setembro de 2007 no Sesc Vila Mariana.

11 Integram atualmente o projeto de pesquisa: André Rostworowski, Elaine de Souza Zanolo Manara, Paula de M. S. Pessoa, Roger Yamaguishi e Thiago Batista Bezerra Costa, com coordenação de Maria Luisa Sandoval Schmidt e Tatiana Freitas Stockler das Neves.

12 O projeto de iniciação científica foi realizado por Ronaldo Lopes Coelho.

13 FAPESP, Fundação de Amparo à Pesquisa de São Paulo e CNPq, Conselho Nacional de Pesquisa, ambos agências de fomento à pesquisa no Brasil. 


\section{PSF e modelo médico-assistencial: duas situações exemplares}

A primeira situação refere-se a uma ameaça de demissão de um número significativo de agentes comunitários vinda de instância superior da Secretaria Municipal de Saúde.

Em uma reunião, a coordenação informa que está sendo pressionada a demitir os agentes comunitários que não vêm cumprindo as "metas de produtividade", traduzidas pelo número de visitas domiciliares realizadas por mês. As visitas domiciliares são uma prática central na estrutura de atendimento do PSF. Elas visam compreender situações de risco e agravos à saúde nas famílias atendidas, bem como acompanhar, informar, orientar, educar, na perspectiva de vigilância em saúde. São, ainda, um dos elos entre o sistema de saúde e a população.

Na origem, sua proposição colocava ênfase no entendimento das necessidades da população com o intuito de alimentar a organização da atenção em saúde de forma adequada às singularidades locais e na criação de vínculos entre os agentes e as famílias tendo em vista a mobilização comunitária e política.

A força e persistência do modelo médico-assistencial, contudo, tende a transformar as visitas domiciliares em dispositivos quase que exclusivos de vigilância, respondendo às demandas do sistema em relação à população (verificação do uso de medicação e do comparecimento a consultas e exames médicos, orientações quanto a cuidados com a saúde, campanhas de vacinação e de controle de endemias e epidemias, detecção de doenças, entre outras) e transformando os agentes em porta-vozes dos especialistas, principalmente dos médicos.

A perspectiva médico-assistencial dá chance para que as visitas sejam consideradas, no plano da gestão, como "metas de produtividade". Nessas metas, observa-se um encolhimento das dimensões qualitativas das visitas tais como: tempo diferenciado de permanência nas casas, privilegiamento das conversas sobre a vida, abertura para imprevistos no agendamento das visitas e sua realização, a visita a uma família ou a um conjunto delas como ponto de partida para o planejamento de ações coletivas, tais como oficinas, encontros, reuniões em torno de questões de interesse comum, apreensão dos limites da família como referência única para o delineamento de políticas para um bairro ou comunidade.

Concomitantemente, a hipervalorização da quantidade de visitas que devem ser feitas mensalmente pelos agentes acaba por defini-las como contatos cada vez mais breves, de caráter prescritivo e de vigilância e como tentativas de fazer a população adequar-se e aderir às normas médicas de cuidado com a saúde, reduzindo as conversas, que poderiam procurar o sentido de práticas de cuidado populares, a falas moralizantes em relação a diferentes modos de vida. Os agentes cunharam a expressão "visita do xizinho": aquela realizada "pró-forma", sem necessidade real, mas, que, no entanto, prejudica a dedicação àquelas que de fato são importantes.

O encaminhamento dado, naquela reunião, à ameaça de demissões, ilustra e reitera a interpretação sobre o lugar que as visitas domiciliares vêm ocupando no PSF, bem como seu caráter aderido ao modelo médico-assistencial na relação com a avaliação do programa.

Para contornar a ameaça de demissões, de início, fica claro, de modo inquestionável que seria necessário aumentar a produtividade, aproximando-se ao máximo das metas estabelecidas alhures. Nessa direção, é feita a proposta de retirar das reuniões de equipe do PSF um tempo a ser direcionado para as visitas, no seguinte esquema: as reuniões diárias evitariam discussões de casos, restringindo-se a despachos e a encaminhamentos e as reuniões semanais de apreciação e discussão do trabalho da equipe naquele período seriam abolidas. $\mathrm{O}$ âmbito de ação dos ACSs ficaria, assim, circunscrito ao cumprimento das metas de visitas domiciliares. 
Embora tenham aparecido propostas de encaminhamento do assunto tais como auxílio mútuo entre ACSs, troca de experiências, problematização da relação entre o PSF e a UBS, havia um saber implícito de que as demissões seriam resolvidas em outro lugar e independentemente das propostas ali aceitas.

Outro aspecto interessante a destacar refere-se ao fato de que a proposta de tentar rever as metas ${ }^{14}$, levantada por um jovem médico, não tenha ganho força. A revisão das metas não pareceu ser possível para os ACSs. Esse episódio parece denunciar que não está no horizonte político dos ACSs uma ação de mudança ou de reivindicação de mudança nas metas. Há, certamente, uma contraposição e uma crítica a seu aspecto quantitativo, mas parece que seu estabelecimento não está ao alcance dos ACSs, como se seu lugar fosse o de executar ou não a determinação ou a ordem vindas "de cima".

A hegemonia do modelo médico-assistencial faz, também, pensar ou questionar qual o sentido de um profissional como o ACS.

A segunda situação emergiu em reunião em que foi tratado um tema candente: "visitas-surpresa" feitas por representantes dos órgãos municipais de saúde.

O objetivo dessas visitas era vistoriar ou fiscalizar a existência de filas para atendimento que haviam sido abordadas, na ocasião, pela mídia televisiva e passaram a ser "proibidas" nas unidades básicas. A falta de agendamento e comunicação sobre as visitas, que vinham ocorrendo em outras unidades também, gerou um clima de desconfiança e de muita tensão, ambas atingindo a credibilidade, a responsabilidade e o empenho dos profissionais da linha de frente do sistema de saúde. Tais ações evidenciaram o controle exercido de modo autoritário pelos gestores e a discrepância entre as requisições feitas por eles e a impossibilidade de seu cumprimento, dadas as condições estruturais existentes nas UBSs. $O$ episódio expõe o "atropelamento" da gestão local pelas instâncias "superiores", bem como as oposições e tensões entre a gestão local e a gestão central. Tratou-se, ainda, das blitz de auditores do Tribunal de Contas, que foram lidas como uma praxe, sempre que acontece a mudança de governo ${ }^{15}$ e cujo significado seria o de uma demonstração de poder por parte do novo governante.

O problema das filas aparece, portanto, em um contexto em que se somam uma campanha contra os serviços públicos de saúde orquestrada pela mídia, a vigilância autoritária sobre a UBS e o ataque de um ato médico ao modelo do $\mathrm{PSF}^{16}$. Os participantes da reunião percebem as filas que se formam em frente ao balcão de recepção da UBS como um sintoma do excesso de demanda por um modelo médico-assistencial, que, apesar das intenções professadas pelo SUS e pelo PSF, continua sendo hegemônico, tanto do ponto de vista da implementação ou concretização das políticas públicas, quanto do das expectativas da população. Os ACSs presentes na reunião discutem sobre a diferença entre entender o ACS como um suplente ou extensão do médico ou como um elemento para estabelecer a ponte entre o sistema de saúde e a população. Recupera-se a história de construção de uma mudança de mentalidade na população que pode aceitar melhor o médico generalista no lugar dos especialistas.

Os ACSs manifestam o receio de que a política jogue fora essas conquistas e insistem na necessidade de criação de tempo e espaço para o trabalho verdadeiramente preventivo e de promoção em saúde. A discussão encaminha-se para as práticas de promoção, tais como o

14 A lei federal que criou o PSF prevê flexibilidade no estabelecimento de metas nas esferas regionais. Essas são negociadas e firmadas nas instâncias do governo municipal, atendendo a interesses políticos e eleitoreiros locais.

15 A referência, nesse caso, é à passagem do governo municipal de José Serra para Gilberto Kassab, na mesma gestão, com a eleição de Serra para o governo estadual.

16 Tratou-se de uma liminar solicitada pelos conselhos de medicina proibindo a atividade de enfermeiros em procedimentos protocolados do PSF, tais como solicitação de exames de rotina, prescrição de certos medicamentos e transcrição de receitas médicas. $\mathrm{O}$ referido ato medico foi proposto para todo o território nacional, afrontando os protocolos já definidos também em nível nacional. 
teatro, o trabalho de fornecer informações, abordagens diferentes das visitas domiciliares feitas na rua ou em bares, entre outras.

Observa-se um movimento interessante de localização dos problemas no âmbito das relações e do cotidiano do trabalho na UBS, tematizando, ainda, as divisões e diferenças entre os profissionais das equipes do PSF (o "felzinho" para os ACSs e o "docinho" para o médico) e entre os profissionais do PSF e os da Prefeitura (ACSs e ATAs). Nesse contexto, aparecem vários elementos que são tomados pelos participantes da reunião como sinais, junto com as filas, dos modos de cuidar e de funcionar da UBS: a queixa tanto de ACSs, quanto de ATAs de serem expostos a críticas dos colegas diante dos usuários; ambos queixavam-se de serem os anteparos dos enfrentamentos com a população; a reclamação de que uns falam mal dos outros, por categorias profissionais, criando guetos ou "panelas"; não seguir procedimentos administrativos ou burocráticos combinados; a dificuldade de localizar prontuários.

Provocados pelo assunto dos prontuários, os participantes trazem questões de fundo, tais como: em que condições é possível cuidar (dos prontuários e dos atendimentos); em que condições é possível admitir um erro; quem arquiva, em que condições o faz.

A relação com o prontuário torna-se metáfora da relação de cuidado com o usuário, mas também do cuidado requerido entre eles, no trabalho. A tensão inicial entre os ACSs e os ATAs em torno da lida com os prontuários permitiu perceber a complexa rede de profissionais que têm contato com os prontuários, fazendo ver a correlação entre diferentes setores e sua corresponsabilidade no seu manuseio e no seu arquivamento. A conversa encaminha-se para a proposta de fazer um mutirão para organizar os arquivos e para a necessidade de entender melhor o trabalho de cada um ou das várias categorias e setores. Surge, ainda, a proposta de realização de uma reunião dos ATAs com os ACSs.

A necessidade de entender melhor o trabalho de cada um e das várias categorias foi tratada a partir de três pontos: a) as diferenças entre o cumprimento de regras e a condição de se constituir um coletivo capaz de questionar as regras exteriores e, também, propor regras pertinentes à singularidade do grupo de trabalho; b) a tensão entre o trabalho prescrito e o trabalho real, ajudando a entender a distância entre o programado e aquilo que pode efetivamente se realizar no cotidiano, atentando para os imprevistos que acontecem com frequência, como, por exemplo, uma agente comunitária que faz visita à creche e ao centro de juventude para levar informações sobre saúde, sendo, no entanto, requisitada a responder à demanda da diretora por orientação sobre como agir em casos de violência doméstica contra crianças; c) a discussão de duas ideias sobre como é melhor trabalhar - individualmente contando com "competências" e "habilidades" pessoais e profissionais, executando com "eficiência" tarefas circunscritas ou cooperativamente, conversando constantemente sobre problemas e organização das tarefas.

Esse tema abre aspectos semelhantes, complementares e de oposição das relações entre usuários e profissionais de saúde. Um médico chama a atenção para o fato de que a população toma a UBS como uma espécie de ouvidoria, relatando ali um conjunto grande de aflições e demandas, em tese, dirigidas aos governos da cidade e do país, tais como, educação, saneamento básico, trabalho e desemprego, alimentação, entre outras. Essa conduta dos usuários requer que os profissionais da UBS pensem em como acolher suas falas sem, necessariamente, atender às demandas que, em grande parte, não dependem do âmbito de ação da unidade básica. Além do acolhimento, há a questão de como compreender e encaminhar as reivindicações para os locais devidos.

A população, por outro lado, pode ter atitudes agressivas em relação aos profissionais da UBS e, especialmente, contra os ACSs, que estendem a porta de entrada da unidade por meio das visitas domiciliares. 
Acolher a população e "sobreviver" às eventuais agressões depende, também, da acolhida que os profissionais encontram em suas equipes e nos colegas de trabalho para tratar em profundidade dos episódios difíceis ou traumáticos. Esse acolhimento ajuda na elaboração afetiva das dificuldades, mas deve ajudar, ainda, a pensar estratégias para lidar com as situações difíceis, principalmente na rua. Essa discussão esclarece o quanto o acolhimento e a conversa são instrumentos, por assim dizer, do planejamento do trabalho.

A oportunidade de trocar experiências e debater estratégias de trabalho faz parte do trabalho, contribuindo para a organização do serviço e para a formação dos profissionais. A troca de experiências permite o estabelecimento de laços de confiança entre os profissionais e o reconhecimento de um saber acumulado sobre a população atendida.

Não por acaso, nesse contexto, os participantes mostram interesse em conhecer o planejamento e as metas estabelecidas nas instâncias superiores para o trabalho que realizam. Nesse contexto, ainda, a organização do serviço, as filas, o descontentamento (da população e dos profissionais) e o mutirão para arrumar o arquivo passam a ser tratados como problemas que dizem respeito a todos.

O deslocamento das pesquisadoras nas reuniões mensais da UBS do lugar inicialmente proposto de coordenadoras para o de observadoras/facilitadoras foi resultado do próprio processo do grupo que usou a presença de psicólogas/pesquisadoras como uma espécie de suporte para a abordagem de temas delicados e conflituosos das relações e do cotidiano de trabalho.

A demanda inicial de que a pesquisa interventiva estruturasse e encaminhasse soluções para o que aparecia como "problemas de relacionamento" em uma dimensão estritamente psicológica foi sendo abandonada na medida em que o grupo apropriou-se das reuniões como oportunidade de formação, tomando a iniciativa de debater, refletir, problematizar e trocar experiências em torno da construção do trabalho.

Nas reuniões predominou um tipo de abertura capaz de abrigar uma pluralidade de ações, tais como a discussão de um assunto ou um acontecimento emergente do cotidiano, a presença de um convidado externo para falar sobre algum tema específico, a avaliação de aspectos práticos da prestação de serviço, a explicitação de diferentes concepções e posições sobre estratégias de atenção básica em saúde, entre outras. Essa pluralidade constituiu-se em contrapartida às representações que assinalavam a reunião produtiva como sendo aquela em que havia rígido planejamento, pauta fixa previamente definida e coordenação autoritária.

As reuniões como espaço de formação, nesse caso, diferem do treinamento e mesmo da educação permanente em saúde, que leva em conta o saber acumulado pelos trabalhadores no exercício de sua profissão, na medida em que não dependem da proposição de cursos destinados a segmentos desses trabalhadores retirados de seu cotidiano de trabalho mas, ao contrário, dependem da vontade política de criar e manter espaços coletivos desse tipo no local de trabalho.

Trata-se de legitimar o trabalho intelectual como trabalho que diz respeito a todos os trabalhadores e de sustentá-lo no interior das instituições de saúde.

A concretização desse tipo de formação incide não só sobre a necessidade de garantir um tempo para o pensar, mas sobre toda a lógica produtivista pautada por metas quantitativas e ritmos "industriais", bem como sobre a ideia de gestão realizada por especialistas (Chaui, 1980). 


\section{Referências}

Alves Sobrinho, E. J. M. \& Capucci, P. F. (2003). Saúde em São Paulo: aspecto da implantação do SUS no período de 2001-2002. Estudos Avançados, 17 (48), 209-227.

Antunes, R. (1999). Os sentidos do trabalho. São Paulo: Boitempo.

Araujo, M. D. (2005). O cotidiano de uma equipe do Programa de Saúde da Família: um olhar genealógico sobre o controle social. Tese de Doutorado, Departamento de Psicologia, Universidade Federal do Espírito Santo, Vitória.

Arendt, H. (1998). O que é política? (fragmentos das obras póstumas compilados por Ursula Ludz). Rio de Janeiro: Bertrand.

Arendt, H. (2008). A promessa da política. Rio de Janeiro: Difel.

Augè, M. (1997). Por uma antropologia dos mundos contemporâneos. Rio de Janeiro: Bertrand.

Augusto, M. H. O. (1989). Políticas públicas, políticas sociais e políticas de saúde: algumas questões para reflexão e debate. Tempo Social, 1 (2), 105-119.

Augusto Junior, F., Silva, L. M. B., Almeida, M. L. \& Silva, P. P. (2009). Terceirização no setor público brasileiro. In D. M. Dau, I. J. Rodrigues \& J. J. Conceição (Orgs.), Terceirização no Brasil: do discurso da inovação à precarização do trabalho (atualização do debate e perspectivas). São Paulo: Annablume.

Bosi, E. (1979). Memória e sociedade: lembranças de velhos. São Paulo: T. A. Queiroz.

Bourdieu, P. (1997). Compreender. In P. Bordieu (Org.), A miséria do mundo. Petrópolis: Vozes.

Bousquat, A., Cohn, A. \& Elias, P. E. (2006). Implantação do Programa Saúde da Família e exclusão sócio-espacial no município de São Paulo. Cadernos de Saúde Pública, 22 (9), 1935-1943.

Brasil. (1997). Ministério da Administração Federal e Reforma do Estado (MARE) \& Secretaria da Reforma do Estado (1997). Organizações Sociais. In Cadernos MARE da Reforma do Estado (vol. 2). Brasília: MARE/DF.

Brasil. (1998). Lei $n^{0}$ 9.637, de 15 de maio de 1998: Dispõe sobre a qualificação de entidades como organizações sociais, a criação do Programa Nacional de Publicização, a extinção dos órgãos e entidades que menciona e a absorção de suas atividades por organizações sociais, e dá outras providências. Brasília.

Brasil. (1999). Lei no 9.790, de 23 de março de 1999: Dispõe sobre a qualificação de pessoas jurídicas de direito privado, sem fins lucrativos, como Organizações da Sociedade Civil de Interesse Público, institui e disciplina o Termo de Parceria, e dá outras providências. Brasília.

Brasil. (2000). Lei Complementar nº 101, de 04 de maio de 2000: Estabelece normas de finanças públicas voltadas para a responsabilidade na gestão fiscal e dá outras providências. Brasília.

Buchabqui, J. A., Capp, E. \& Petuco, D. R. S. (2006). Convivendo com agentes de transformação: a interdisciplinaridade no processo de ensino/aprendizado em saúde. Revista Brasileira de Educação Médica, $30(1), 32-38$.

Campos, G. W. S. (1999). Equipes de referência e apoio especializado matricial: uma proposta de reorganização do trabalho em saúde. Ciência e Saúde Coletiva, 4 (2), 393-404.

Certeau, M. (1994). A invenção do cotidiano: artes de fazer. Petrópolis: Vozes.

Chaui, M. S. (1980). Cultura e democracia: o discurso competente e outras falas. São Paulo: Moderna.

Cohn, A. (2003). Estado e sociedade e as reconfigurações do direito à saúde. Ciência Eु Saúde Coletiva, 8 (1), 9-18.

Cohn, A. \& Elias, P. E. M. (2005). Saúde no Brasil: políticas e organização de serviços. São Paulo: Cortez, CEDEC.

Cohn, A. (2005). A saúde na previdência social e na seguridade social: antigos estigmas e novos desafios. In A. Cohn, A. \& P. E. M. Elias (Orgs.), Saúde no Brasil: políticas e organização de serviços. São Paulo: Cortez, CEDEC.

Critelli, D. M. (1996). Analítica do sentido: uma aproximação e interpretação do real de orientação fenomenológica. São Paulo: Brasiliense.

Druck, G. \& Franco, T. (Orgs.). (2007). A perda da razão social do trabalho: a terceirização e precarização. São Paulo: Boitempo.

Foucault, M. (1980). História da sexualidade I: a vontade de saber. (3ª ed.). Rio de Janeiro: Graal.

Foucault, M. (1981). Microfísica do poder (2ª ed.). Rio de Janeiro: Graal. 
Geertz, C. (1989a). A interpretação das culturas. Rio de Janeiro: LTC.

Geertz, C. (1989b). El antropólogo como autor. Buenos Aires: Paidós.

Gil, C. R. R. (2005). Formação de recursos humanos em saúde da família: paradoxos e perspectivas. Cadernos de Saúde Pública, 21 (2), 490-498.

Gonçalves, W. (1998). Parecer sobre terceirização e parcerias na saúde pública. Artigo disponível em: http://www.datasus.gov.br/cns/temas/WAGTERC.htm

Junqueira, V. (2001). Saúde na cidade de São Paulo (1989 a 2000). São Paulo: Polis, Educ.

Lotta, G. S. (2006). Saber e poder: agentes comunitários de saúde aproximando saberes locais e políticas públicas. Tese de Doutorado, Fundação Getúlio Vargas, Escola de Administração de Empresas de São Paulo, São Paulo.

Montaño, C. E. (2002). O projeto neoliberal de resposta à "questão social" e a funcionalidade do terceiro setor. Revista Lutas Sociais, 8, 53-64.

Neves, T. F. S. (2006). Ensaios sobre o desemprego: qualidades de um "novo" trabalhador? Imaginário, 12 (13), 123. 141.

Nunes, M. O., Trad., L. B., Almeida, B. A., Homem, C. R. \& Melo, M. C. I. C. (2002). O agente comunitário de saúde: construção da identidade desse personagem híbrido e polifônico. Cadernos de Saúde Pública, 18 (6), $1639-1646$.

Oliveira, F. (2001). Aproximações ao enigma: o que quer dizer desenvolvimento local? São Paulo: Pólis, FGV.

Oliveira, R. C. (2006). O trabalho do antropólogo. São Paulo: Unesp.

Paoli, M. C. (1994). Os direitos do trabalho e sua justiça. Revista da USP, 21, 100-115.

Patto, M. H. S. (2009). Para ler as entrevistas. In M. H. S. Patto (Org.), A cidadania negada: políticas públicas e formas de viver. São Paulo: Casa do Psicólogo.

Pierantoni, C. R. (2001). As reformas do Estado, da saúde e recursos humanos: limites e possibilidades. Ciência $\mathfrak{E}$ Saúde Coletiva, 6 (2), 341-360.

Sato, L. (2002). Prevenção de agravos à saúde do trabalhador: replanejando o trabalho através das negociações cotidianas. Cadernos de Saúde Pública, 18 (5), 1147-1166.

Schmidt, M. L. S. (2003). Política públicas e saúde mental. In Z. A. Trindade \& A. N. Andrade (Orgs.), Psicologia e saúde: um campo em construção. São Paulo: Casa do Psicólogo.

Schmidt, M. L. S. (2006). Pesquisa participante: alteridade e comunidades interpretativas. Psicologia USP, 17 (2), $11-41$.

Schmidt, M. L. S. (2008). Pesquisa participante e formação ética do pesquisador na área de saúde. Ciência Eु Saúde Coletiva, 13 (2), 391-398.

Secretaria Municipal de Saúde de São Paulo (2001). Comunicado no 4. Diretrizes gerais para a SMS: Implantação do Programa de Saúde da Família. Diário Oficial da cidade de São Paulo, 16.

Secretaria Municipal de Saúde de São Paulo (2009). Portaria 1590/2009. Diário Oficial da Cidade de São Paulo, 54 (170), 24-25.

Spink, P. K. (1996). A organização como fenômeno psicossocial: notas para a redefinição da psicologia do trabalho. Psicologia e Sociedade, 8 (1), 147-192.

Silva, J. A. \& Dalmaso, A. S. W. (2002). Agente comunitário de saúde: o ser, o saber, o fazer. Rio de Janeiro: Fiocruz.

Silva Junior, J. R. \& Sguissardi, V. (1999). Novas faces da educação superior: reformas do estado e mudanças na produção. Bragança Paulista: Edusf.

Viana, A. L. D. \& Dal Poz, M. R. (2005). A reforma do Sistema de Saúde no Brasil e o Programa de Saúde da Família. Physis: Revista de Saúde Coletiva, 15 (suplemento), 225-164.

\section{Endereço para correspondência}

maluschmidt@terra.com.br, taneves@usp.br 